\title{
Avaliação das Posturas Adotadas em Operações Florestais em Áreas Declivosas
}

\author{
Nilton Cesar Fiedler, Renan Pereira Barbosa, Bruno Camata Andreon, Saulo \\ Boldrini Gonçalves, Elizabeth Neire da Silva
}

Departamento de Engenharia Florestal, Universidade Federal do Espírito Santo - UFES

\begin{abstract}
RESUMO
Esta pesquisa teve o objetivo de avaliar os fatores que interferem e alteram os modelos biomecânicos posturais adequados durante as etapas de implantação e manutenção florestal, a fim de sugerir a adoção de posturas corretas durante a execução das operações florestais. A pesquisa foi realizada em propriedades rurais no sul do Estado do Espírito Santo, onde há o predomínio de relevo declivoso. As posturas foram analisadas em cada etapa da implantação (roçada semimecanizada, coveamento manual, coveamento semimecanizado, adubação e plantio) e da manutenção florestal (coroamento, adubação, desrama manual e desrama semimecanizada). Os dados foram obtidos utilizando-se vídeo filmagem e analisados por meio do método OWAS de análise de posturas no trabalho, gerando posturas padrões. Baseando-se nos resultados, concluiu-se que as posturas adotadas nas operações de coroamento, coveamento manual, coveamento mecanizado, roçada mecânica e desrama manual foram consideradas críticas, necessitando de correções em futuro próximo.
\end{abstract}

Palavras-chave: ergonomia florestal, biomecânica, implantação florestal, manutenção florestal.

\section{Evaluation of the Postures Adopted in Forestry Operations in Declivous Areas}

\begin{abstract}
The purpose of this research was to evaluate the factors that intervene and alter the biomechanical models adequate posture during the stage of implantation and forest maintenance, in order to suggest the adoption of the correct posture during the execution of forest operations. The research was carried out in farms in the south of the State of the Espirito Santo, Brazil, where there is a predominance of declivous relief. The postures were analyzed in each stage of the implantation (semi-mechanized mowing, manual and semi-mechanized tillage, fertilization and planting) and of the forest maintenance (crown, fertilization, manual and semi-mechanized pruning). The data were obtained using video filming and were analyzed using the OWAS method of analysis of positions in the work, generating standard postures. Based on the results, it was concluded that the postures adopted in the operations of crown, manual and mechanized tillage, mechanical mowing, and manual pruning were considered critical and need corrections in a near future.
\end{abstract}

Keywords: ergonomics, biomechanical models, forestry implementation, maintenance. 


\section{INTRODUÇÃO}

Tem-se notado uma grande preocupação com a melhoria da saúde, do bem-estar e da segurança do trabalhador no ambiente de trabalho, de forma a melhorar a qualidade de vida do trabalhador. Para que se possam obter qualidade e satisfação no trabalho, é necessário adotar práticas de planejamento, controle e monitoramento das atividades.

Segundo a IEA (International..., 2000), ergonomia é a ciência que trata das interações entre o ser humano e outros elementos do sistema, e que aplica teorias, princípios, dados, métodos a projetos que visam otimizar o bem-estar do ser humano. Essa ciência é considerada interdisciplinar e tem a função de modificar condições inadequadas de trabalho e prevenir e tratar as patologias ocupacionais.

Montmollin (1990) define condições de trabalho como tudo o que caracteriza uma situação de trabalho e que permite ou impede a atividade dos trabalhadores. As condições de trabalho na implantação e manutenção florestal, principalmente em áreas declivosas, em geral, são árduas e pesadas, exigindo grande esforço físico do trabalhador, podendo causar-lhe desconforto durante a execução das operações. Esses trabalhos, muitas vezes, são realizados de forma incorreta e com intensidade elevada, podendo gerar um déficit na saúde e causar problemas na coluna e lombalgias.

A postura é a organização dos segmentos corporais no espaço, expressa pela imobilização das partes do esqueleto em determinadas posições, solidárias umas com as outras, e que conferem ao corpo uma atitude de conjunto. Essa atitude indica o modo pelo qual o organismo enfrenta os estímulos do mundo exterior e se prepara para reagir. A postura submete-se às características anatômicas e fisiológicas do corpo humano e possui um estreito relacionamento com a atividade do indivíduo, sendo que a mesma pessoa adota diferentes posturas nas mais variadas atividades (Vosniak, 2010; Iida, 2005).

No setor florestal, o manejo manual de cargas e as posturas desconfortáveis podem se apresentar como um problema ergonômico, representando um dos principais fatores de risco de lesões da classe trabalhadora, que necessitará de tratamento e reabilitação (Espinosa, 1999). O aparecimento de sintomas de fadiga por sobrecarga física depende do esforço desenvolvido, da duração do trabalho e das condições individuais, como estados de saúde, nutrição e condicionamento decorrente da prática da atividade. À medida que aumenta a fadiga, reduzemse o ritmo de trabalho, a atenção e a rapidez de raciocínio, tornando o operador menos produtivo e mais sujeito a erros e acidentes (Silva, 1999).

Nota-se grande dificuldade na identificação e no registro das posturas adotadas no trabalho, tornando a avaliação e a correção dessas posturas ainda mais complexas. Normalmente, as avaliações são realizadas de forma subjetiva e com base nas reclamações dos próprios trabalhadores, quando, muitas vezes, a solução surge quando o funcionário já apresenta lesões lombares (Vosniak, 2010). Dessa forma, surgiram diversos modelos de avaliação biomecânica para análise de postura. Dentre estes, o OWAS, o qual estipula normas e recomendações ergonômicas que determinam a classe de correção das posturas exercidas na operação.

Segundo Alves et al. (2000), as avaliações ergonômicas têm contribuído significativamente para a melhoria das condições de trabalho humano, incrementando a qualidade de vida, que é condição essencial para o êxito de uma empresa ou de um empreendimento.

Dessa forma, há a necessidade de analisar o trabalho a fim de encontrar medidas corretivas para que haja melhoria da segurança, do manuseio de cargas, das posturas, do conforto e do bem-estar do trabalhador, levando, assim, ao aumento da produtividade e da qualidade de vida no trabalho.

Inserida nesse contexto, esta pesquisa objetivou analisar as posturas adotadas pelos trabalhadores em operações florestais em áreas declivosas no sul do Estado do Espírito Santo, visando conhecer o cenário atual e propor a melhoria e a correção das posturas e das cargas físicas de trabalho realizadas na implantação e na manutenção florestal, quando necessárias, de forma a contribuir com a melhoria da qualidade de vida do trabalhador florestal.

\section{MATERIAL E MÉTODOS}

Esta pesquisa foi realizada em atividades de implantação e manutenção de povoamentos 
florestais de eucalipto em áreas declivosas no sul do Estado do Espírito Santo. As áreas de implantação eram pertencentes a pequenos produtores rurais, com plantios entre 2 e 18 ha. A inclinação do terreno variou entre 28 e $43 \%$. As atividades avaliadas foram: roçada semimecanizada, coveamento manual, coveamento semimecanizado, plantio, coroamento manual, adubação manual, desrama manual e desrama semimecanizada. A descrição das atividades é mostrada na Tabela 1.

Os dados foram coletados no período de novembro de 2009 a abril de 2010 em propriedades rurais, situadas nos municípios de Jerônimo Monteiro (coordenadas geográficas $20^{\circ} 47^{\prime} 22^{\prime \prime} \mathrm{S}$ e $41^{\circ} 23^{\prime} 42^{\prime \prime} \mathrm{O}$ de Greenwich com altitude de $110 \mathrm{~m}$ ) e Alegre (coordenadas geográficas $20^{\circ} 45^{\prime} 49^{\prime \prime} \mathrm{S}$ e $41^{\circ} 31^{\prime} 57^{\prime \prime} \mathrm{O}$ de Greenwich com altitude de $254 \mathrm{~m}$ ). A temperatura média anual é $22,2^{\circ} \mathrm{C}$, variando entre 16,9 e $29,0^{\circ}$. O clima é quente e úmido no verão e seco no inverno. A precipitação média anual é de $1240 \mathrm{~mm}$.

Realizaram-se filmagens dos trabalhadores utilizando-se uma câmera filmadora de marca Sony modelo DCR-SR87, com monitoramento dos movimentos e posições em cada atividade florestal executada. Inicialmente, foi feito um levantamento piloto para definir o numero mínimo de amostras necessárias para um erro amostral máximo de 5\%.
Para análise das filmagens, as imagens foram congeladas, os ângulos das articulações medidos e as posições verificadas. $\mathrm{Na}$ análise dos resultados, utilizou-se o conteúdo do sistema OWAS ("Ovaco Working Posture Analyzing System”), de origem finlandesa. Essa ferramenta ergonômica auxiliou na análise e na avaliação das posturas nas atividades prédeterminadas, caracterizando a postura das costas, dos braços, das pernas e ainda o esforço realizado durante a execução da tarefa, conforme indicado a seguir:

a) Posição das costas:

1) Ereta;

2) Inclinada;

3) Ereta e torcida ou com curso lateral em curva;

4) Curvada e torcida ou curvada para frente e curso lateral.

b) Posição dos braços:

1) Ambos abaixo do nível do ombro;

2) Um acima do nível do ombro;

3) Ambos acima do nível do ombro.

c) Posição das pernas:

1) Sentado, com as pernas abaixo do nível das nádegas;

2) Em pé, exercendo força em ambas as pernas;

3) Em pé, exercendo força em uma única perna;

4) Em pé ou abaixado em ambos os pés, com as pernas flexionadas;

5) Em pé ou abaixado com um pé e perna articulada;

6) Ajoelhado com um ou ambos os joelhos.

Tabela 1. Descrição das operações florestais analisadas.

Table 1. Description of forest operations analysis.

Operações Florestais

Roçada semimecanizada

Coveamento manual

Coveamento semimecanizado

Plantio

Coroamento manual

Adubação manual

Desrama manual

Desrama semimecanizada
Processo de limpeza no terreno, no qual se retiram plantas indesejáveis da área, com a utilização de uma roçadeira costal semimecanizada (motorroçadeira).

Procedimento de escavação do solo para o plantio. Utiliza-se o enxadão como ferramenta de trabalho.

Procedimento de escavação do solo para o plantio. Utiliza-se o motocoveador como ferramenta de trabalho.

Processo de fixação manual da muda no solo.

Eliminação de invasoras ao redor da muda (ćŕrculo). Atividade realizada com enxada em raio médio de $60 \mathrm{~cm}$.

Distribuição manual do adubo nas laterais da muda, a lanço. O tipo e dosagem dos adubos variam conforme resultado de análise de solo.

Eliminação dos galhos inferiores à copa das árvores, realizado com o intuito de diminuir a quantidade de nós na madeira. Usada a foice com cabo longo (3 $\mathrm{m}$ de comprimento) como ferramenta de trabalho. Eliminação dos galhos inferiores à copa das árvores com motopoda.

Fonte: Elaborado pelos autores. 
7) Andando ou movimentando.

d) Peso ou força requerida:

1) Carga menor ou igual a $10 \mathrm{~kg}$;

2) Carga maior que $10 \mathrm{~kg}$ e menor que $20 \mathrm{~kg}$;

3) Carga maior que $20 \mathrm{~kg}$.

$\mathrm{Na}$ análise, verificou-se a posição mais frequente em cada operação de implantação e manutenção florestal, visando identificar as posturas adotadas corretamente e aquelas que precisam de correções. $\mathrm{Na}$ obtenção das posturas padrões, utilizou-se a metodologia de pausas nas filmagens em um intervalo de cinco segundos para observar qual posição mais se repetia durante a operação. Todas as cargas manuseadas foram pesadas com o uso de uma balança com precisão de $1 \mathrm{~g}$. Após a definição das posturas padrões, definiram-se os mecanismos de ação e a necessidade de correção das posturas adotadas, de acordo com a Tabela 2, conforme o modelo OWAS.

\section{RESULTADOS E DISCUSSÃO}

$\mathrm{Na}$ avaliação e na análise dos dados, obtiveramse os resultados para cada operação florestal, bem como suas posturas padrões, porcentagem de cada posicionamento e principais problemas ocasionados devido a tal atividade. Os resultados estão apresentados por atividade, conforme Tabela 3.

$\mathrm{Na}$ atividade de roçada semimecanizada, a postura mais comumente utilizada foi a $2 / 1 / 7 / 1$ (costas inclinadas, ambos os braços abaixo do nível do ombro, andando ou se movendo e carga menor que $10 \mathrm{~kg}$ ), tendo também a presença das posturas 2/1/3/1, 2/1/2/1 e 4/1/3/1 com grande percentual.

Os resultados apresentados na Tabela 3 mostram que o posicionamento com maior número de repetições no coveamento manual foi o $2 / 1 / 3 / 1$ (costas

Tabela 2. Categorias de ação de acordo com o modelo OWAS.

Table 2. Action categories according to the OWAS model.

\begin{tabular}{|ll|}
\hline Classe 1 & Não são necessárias medidas corretivas. \\
Classe 2 & $\begin{array}{l}\text { São necessárias correções em um futuro } \\
\text { próximo. }\end{array}$ \\
Classe 3 & $\begin{array}{l}\text { São necessárias correções tão logo quanto } \\
\text { possível. }\end{array}$ \\
Classe 4 & São necessárias correções imediatas. \\
\hline
\end{tabular}

inclinadas, ambos os braços abaixo do nível do ombro, em pé, exercendo força em uma única perna e carga menor que $10 \mathrm{~kg}$ ). A posição foi repetida 183 vezes em um total de 364 , equivalendo a $50,27 \%$ de todas as posturas adotadas no trabalho. Considerando-se uma carga de 8 horas diárias, a posição padrão foi responsável por 4,02 horas. Problemas de coluna seriam as principais consequências em longo prazo, necessitando correções das posturas em um futuro próximo.

No coveamento semimecanizado, a postura padrão foi a 2/1/4/2, ou seja, costas inclinadas, ambos os braços abaixo do nível do ombro, de pé ou agachado com ambos os joelhos flexionados e carga entre 10 e $20 \mathrm{~kg}$, sendo repetida durante 25,38\% de todas as posturas exercidas. A união das costas inclinadas sob efeito de carga entre 10 e $20 \mathrm{~kg}$ acoplada à desgastante postura das pernas pode causar graves problemas à coluna, sendo verificada a necessidade de novas formas de operação ou novas máquinas, como futuras correções. Ambas as operações de coveamento (manual e semimecanizada) necessitam de correções.

No plantio, a postura padrão foi $1 / 1 / 7 / 1$, o que corresponde a costas eretas, ambos os braços abaixo do nível do ombro, andando ou se movendo e carga menor que $10 \mathrm{~kg}$.

A postura padrão da atividade de coroamento foi a 2/1/3/1 (costas inclinadas, ambos os braços abaixo do nível do ombro, em pé, exercendo força em uma única perna e carga menor que $10 \mathrm{~kg}$ ). Tal postura foi executada por $60,87 \%$ da jornada de trabalho, o que totaliza 4,87 horas em uma carga diária de 8 horas. São necessárias correções em um futuro próximo, adaptando novas ferramentas ergonômicas, diminuindo a carga física de trabalho ou criando novas formas de operação, com o intuito de evitar futuros problemas físicos, ocasionados pela continuidade de posturas desconfortáveis.

O posicionamento padrão da atividade de adubação manual de cobertura foi o $1 / 1 / 7 / 2$ (costas eretas, ambos os braços abaixo do nível do ombro, andando ou se movendo e carga entre 10 e $20 \mathrm{~kg}$ ). Essa postura obteve 78 repetições de 171 totais, sendo responsável por $45,61 \%$ de todos os posicionamentos, que, em uma carga horária de 8 horas/dia, representa 3,65 horas. 
Tabela 3. Análise das posturas nas atividades de acordo com o método OWAS.

Table 3. Posture analysis according of the OWAS method.

\begin{tabular}{|c|c|c|c|c|c|}
\hline Atividade & Posição & Repetição & $\%$ & $\mathbf{T}^{*}$ & Classe \\
\hline \multirow{11}{*}{$\begin{array}{l}\text { Roçada } \\
\text { semimecanizada }\end{array}$} & $2 / 1 / 7 / 1$ & 32 & 14,95 & 1,20 & 2 \\
\hline & $2 / 1 / 3 / 1$ & 30 & 14,02 & 1,12 & 2 \\
\hline & $2 / 1 / 2 / 1$ & 28 & 13,08 & 1,05 & 2 \\
\hline & $4 / 1 / 3 / 1$ & 28 & 13,08 & 1,05 & 2 \\
\hline & $1 / 1 / 3 / 1$ & 20 & 9,35 & 0,75 & 1 \\
\hline & $1 / 1 / 7 / 1$ & 20 & 9,35 & 0,75 & 1 \\
\hline & $1 / 1 / 2 / 1$ & 20 & 9,35 & 0,75 & 1 \\
\hline & $3 / 1 / 3 / 1$ & 18 & 8,41 & 0,67 & 1 \\
\hline & $3 / 1 / 2 / 1$ & 10 & 4,67 & 0,37 & 1 \\
\hline & $4 / 1 / 2 / 1$ & 8 & 3,74 & 0,30 & 2 \\
\hline & Total & 214 & 100 & 8 & 2 \\
\hline \multirow{11}{*}{$\begin{array}{l}\text { Coveamento } \\
\text { manual }\end{array}$} & $2 / 1 / 3 / 1$ & 183 & 50,27 & 4,02 & 2 \\
\hline & $2 / 1 / 4 / 1$ & 58 & 15,93 & 1,27 & 3 \\
\hline & $1 / 1 / 7 / 1$ & 52 & 14,29 & 1,14 & 1 \\
\hline & $2 / 2 / 3 / 1$ & 25 & 6,87 & 0,55 & 2 \\
\hline & $1 / 1 / 2 / 1$ & 19 & 5,22 & 0,42 & 1 \\
\hline & $2 / 1 / 2 / 1$ & 9 & 2,47 & 0,20 & 2 \\
\hline & $4 / 2 / 3 / 1$ & 5 & 1,37 & 0,11 & 3 \\
\hline & $4 / 2 / 4 / 1$ & 5 & 1,37 & 0,11 & 4 \\
\hline & $2 / 2 / 4 / 1$ & 5 & 1,37 & 0,11 & 3 \\
\hline & $1 / 1 / 3 / 1$ & 3 & 0,82 & 0,07 & 1 \\
\hline & Total & 364 & 100 & 8 & 2 \\
\hline \multirow{11}{*}{$\begin{array}{l}\text { Coveamento } \\
\text { semimecanizado }\end{array}$} & $2 / 1 / 4 / 2$ & 66 & 25,38 & 2,03 & 3 \\
\hline & $4 / 1 / 2 / 2$ & 54 & 20,77 & 1,66 & 2 \\
\hline & $4 / 1 / 3 / 2$ & 44 & 16,92 & 1,35 & 2 \\
\hline & $2 / 1 / 3 / 2$ & 20 & 7,69 & 0,62 & 2 \\
\hline & $2 / 1 / 2 / 2$ & 16 & 6,15 & 0,49 & 2 \\
\hline & $4 / 1 / 4 / 2$ & 16 & 6,15 & 0,49 & 4 \\
\hline & $2 / 1 / 2 / 1$ & 16 & 6,15 & 0,49 & 2 \\
\hline & $1 / 1 / 2 / 1$ & 12 & 4,62 & 0,37 & 1 \\
\hline & $2 / 1 / 7 / 2$ & 12 & 4,62 & 0,37 & 3 \\
\hline & $1 / 1 / 2 / 2$ & 4 & 1,54 & 0,12 & 1 \\
\hline & Total & 260 & 100 & 8 & 3 \\
\hline \multirow{8}{*}{ Plantio } & $1 / 1 / 7 / 1$ & 72 & 31,86 & 2,55 & 1 \\
\hline & $2 / 1 / 6 / 1$ & 41 & 18,14 & 1,45 & 2 \\
\hline & $2 / 1 / 3 / 1$ & 38 & 16,81 & 1,35 & 2 \\
\hline & $1 / 1 / 2 / 1$ & 29 & 12,83 & 1,03 & 1 \\
\hline & $2 / 1 / 4 / 1$ & 20 & 8,85 & 0,71 & 3 \\
\hline & $1 / 1 / 3 / 1$ & 18 & 7,96 & 0,64 & 1 \\
\hline & $2 / 1 / 5 / 1$ & 8 & 3,54 & 0,28 & 3 \\
\hline & Total & 226 & 100 & 8 & 1 \\
\hline \multirow{9}{*}{$\begin{array}{l}\text { Coroamento } \\
\text { manual }\end{array}$} & $2 / 1 / 3 / 1$ & 84 & 60,87 & 4,87 & 2 \\
\hline & $2 / 1 / 2 / 1$ & 25 & 18,12 & 1,45 & 2 \\
\hline & $1 / 1 / 3 / 1$ & 15 & 10,87 & 0,87 & 1 \\
\hline & $1 / 1 / 2 / 1$ & 7 & 5,07 & 0,41 & 1 \\
\hline & $4 / 1 / 3 / 1$ & 3 & 2,17 & 0,17 & 2 \\
\hline & $2 / 1 / 4 / 1$ & 2 & 1,45 & 0,12 & 3 \\
\hline & $4 / 1 / 2 / 1$ & 1 & 0,72 & 0,06 & 2 \\
\hline & $1 / 2 / 3 / 1$ & 1 & 0,72 & 0,06 & 1 \\
\hline & Total & 138 & 100 & 8 & 2 \\
\hline
\end{tabular}

$\mathrm{T}^{*}$ : tempo, em horas, na posição durante uma carga diária de 8 horas de trabalho. 
Tabela 3. Continuação...

Table 3. Continuação...

\begin{tabular}{|c|c|c|c|c|c|}
\hline Atividade & Posição & Repetição & $\%$ & $T^{\star}$ & Classe \\
\hline \multirow{6}{*}{$\begin{array}{l}\text { Adubação } \\
\text { manual }\end{array}$} & $1 / 1 / 7 / 2$ & 78 & 45,61 & 3,65 & 1 \\
\hline & $1 / 1 / 7 / 1$ & 69 & 40,35 & 3,23 & 1 \\
\hline & $1 / 1 / 2 / 1$ & 12 & 7,02 & 0,56 & 1 \\
\hline & $1 / 1 / 3 / 1$ & 6 & 3,51 & 0,28 & 1 \\
\hline & $1 / 1 / 3 / 2$ & 6 & 3,51 & 0,28 & 1 \\
\hline & Total & 171 & 100 & 8 & 1 \\
\hline \multirow{9}{*}{$\begin{array}{l}\text { Desrama } \\
\text { manual }\end{array}$} & $2 / 1 / 3 / 1$ & 80 & 39,22 & 3,14 & 2 \\
\hline & $1 / 1 / 3 / 1$ & 36 & 17,65 & 1,41 & 1 \\
\hline & $2 / 1 / 2 / 1$ & 24 & 11,76 & 0,94 & 2 \\
\hline & $1 / 1 / 2 / 1$ & 24 & 11,76 & 0,94 & 1 \\
\hline & $1 / 1 / 7 / 1$ & 20 & 9,80 & 0,78 & 1 \\
\hline & $4 / 1 / 3 / 1$ & 8 & 3,92 & 0,31 & 2 \\
\hline & $1 / 2 / 2 / 1$ & 6 & 2,94 & 0,24 & 1 \\
\hline & $3 / 1 / 3 / 1$ & 6 & 2,94 & 0,24 & 1 \\
\hline & Total & 204 & 100 & 8 & 2 \\
\hline \multirow{9}{*}{$\begin{array}{l}\text { Desrama } \\
\text { semimecanizada }\end{array}$} & $1 / 1 / 3 / 1$ & 49 & 22,69 & 1,81 & 1 \\
\hline & $2 / 1 / 3 / 1$ & 44 & 20,37 & 1,63 & 2 \\
\hline & $1 / 1 / 7 / 1$ & 41 & 18,98 & 1,52 & 1 \\
\hline & $1 / 1 / 2 / 1$ & 25 & 11,57 & 0,93 & 1 \\
\hline & $2 / 1 / 7 / 1$ & 18 & 8,33 & 0,67 & 2 \\
\hline & $2 / 1 / 2 / 1$ & 17 & 7,87 & 0,63 & 2 \\
\hline & $4 / 1 / 3 / 1$ & 12 & 5,56 & 0,44 & 2 \\
\hline & $2 / 1 / 4 / 1$ & 10 & 4,63 & 0,37 & 3 \\
\hline & Total & 216 & 100 & 8 & 1 \\
\hline
\end{tabular}

$\mathrm{T}^{*}$ : tempo, em horas, na posição durante uma carga diária de 8 horas de trabalho.

Observando-se os resultados apresentados na Tabela 3, nota-se que, na operação de desrama manual, o posicionamento com maior número de repetições foi o 2/1/3/1, semelhante ao coveamento manual, ou seja, costas inclinadas, ambos os braços abaixo do nível do ombro, em pé, exercendo força em uma única perna e carga menor que $10 \mathrm{~kg}$. Essa posição padrão corresponde a $39,22 \%$ do tempo total de trabalho, ou seja, 3,14 horas considerando-se uma jornada de trabalho diária de 8 horas.

$\mathrm{Na}$ execução da desrama semimecanizada, a postura que caracterizou a operação foi $1 / 1 / 3 / 1$ (costas eretas, ambos os braços abaixo do nível do ombro, em pé, exercendo força em uma única perna e carga menor que $10 \mathrm{~kg}$ ), responsável por $22,69 \%$ do total analisado. Tal postura não requer correções, não sendo considerado prejudicial ao bem estar físico. Os posicionamentos adotados na desrama manual são mais prejudiciais que os posicionamentos na desrama semimecanizada.

A Figura 1 representa todas as posturas adotadas nas atividades de implantação e manutenção de povoamentos florestais e respectivas repetições.

Verifica-se que a posição mais utilizada durante todas as etapas de implantação e manutenção foi a 2/1/3/2 (costas inclinadas, ambos os braços abaixo do nível do ombro, em pé, exercendo força em uma única perna e carga menor que $10 \mathrm{~kg}$ ), posicionamento que exige correções em um futuro próximo, uma vez que se enquadra na classe 2 do modelo OWAS.

Com base nos resultados encontrados para cada atividade, as posturas padrões e respectivos mecanismos de ação são sintetizados na Tabela 4.

De todas as operações analisadas, as piores posturas foram adotadas pelos trabalhadores na 


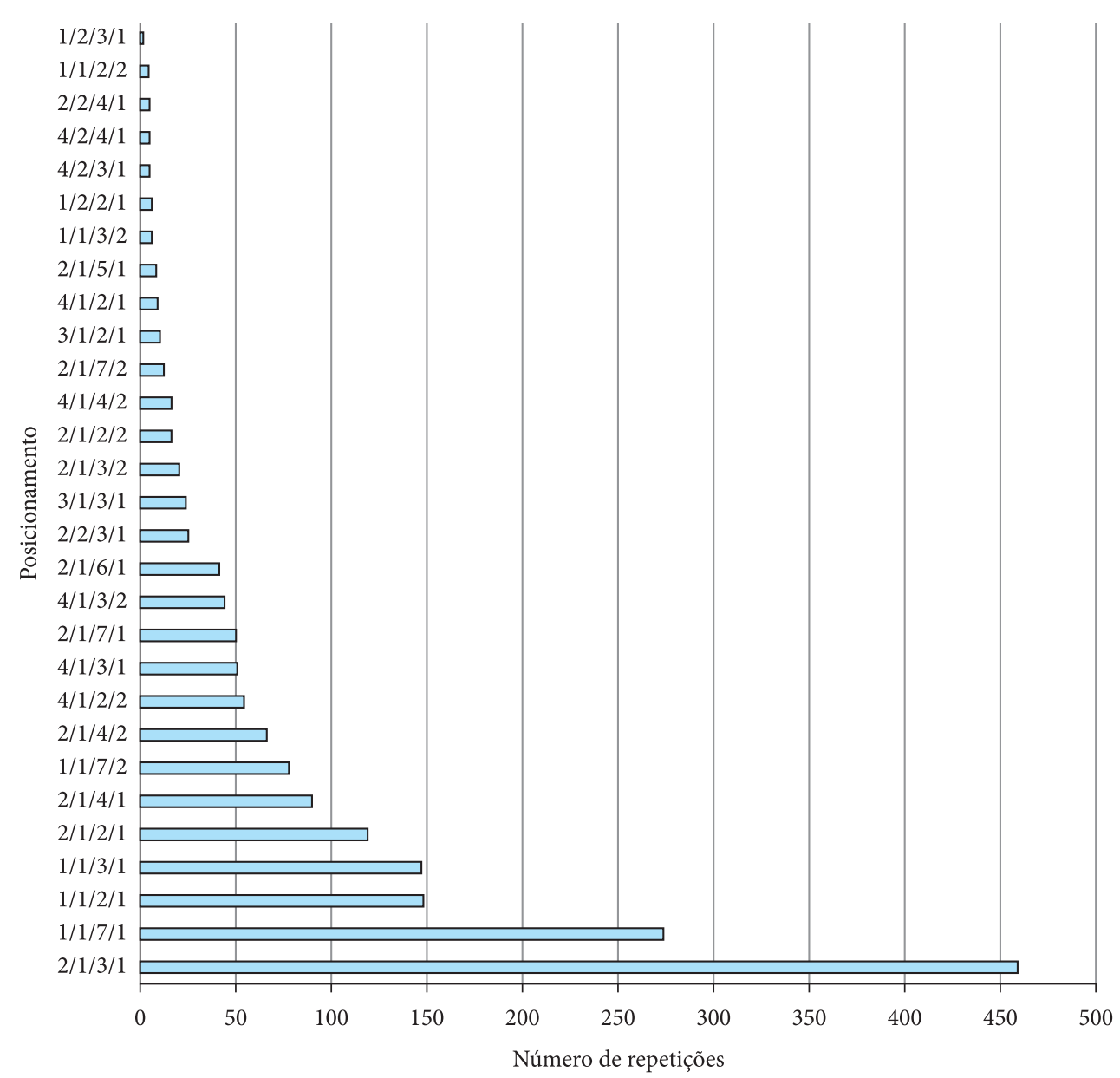

Figura 1. Posturas e suas repetições na implantação e na manutenção florestal.

Figure 1. Postures and repetitions in forest implantation and maintenance.

Tabela 4. Posições padrão de cada atividade e respectiva categoria de ação de acordo com o modelo OWAS.

Table 4. Standard Positioning of each activity and respective category of action according to the OWAS model.

\begin{tabular}{|c|c|c|}
\hline Atividades & Posições padrão & Categoria de ação de acordo com o modelo OWAS \\
\hline Roçada semimecanizada & $2 / 1 / 7 / 1$ & Classe 2 - São necessárias correções em um futuro próximo \\
\hline Coveamento manual & $2 / 1 / 3 / 1$ & Classe 2 - São necessárias correções em um futuro próximo \\
\hline Coveamento semimecanizado & $2 / 1 / 4 / 2$ & Classe 3 - São necessárias correções tão logo quanto possível \\
\hline Plantio & $1 / 1 / 7 / 1$ & Classe 1 - Não são necessárias medidas corretivas \\
\hline Coroamento manual & $2 / 1 / 3 / 1$ & Classe 2 - São necessárias correções em um futuro próximo \\
\hline Adubação manual & $1 / 1 / 7 / 2$ & Classe 1 - Não são necessárias medidas corretivas \\
\hline Desrama manual & $2 / 1 / 3 / 1$ & Classe 2 - São necessárias correções em um futuro próximo \\
\hline Desrama semimecanizada & $1 / 1 / 3 / 1$ & Classe 1 - Não são necessárias medidas corretivas \\
\hline
\end{tabular}

atividade de coveamento semimecanizado, seguido da roçada semimecanizada, do coveamento manual, do coroamento manual e da desrama manual. De uma maneira geral, a adoção de treinamentos para uso correto das máquinas e ferramentas, e pequenas intervenções nos projetos surtem grandes efeitos positivos na melhoria da postura adotada pelos trabalhadores. Esses ensinamentos contribuirão muito para uma performance contínua na atividade sem um desgaste excessivo do operador. 


\section{CONCLUSÕES}

De acordo com os resultados obtidos, conclui-se que:

- As atividades de coroamento, coveamento manual, coveamento semimecanizado, desrama manual e roçada semimecanizada necessitam de correções, pois podem gerar problemas de coluna dentre outros problemas que afetam o bem-estar físico;

- Nas operações de adubação, plantio e desrama semimecanizada, não há a necessidade de medidas corretivas com relação às posturas, sendo estas consideradas satisfatórias;

- A operação em que as posturas adotadas foram mais prejudiciais durante sua execução foi o coveamento semimecanizado, obtendo, também, o pior resultado com relação às costas e pernas, necessitando que sejam adotadas medidas corretivas rápidas, como treinamentos específicos e correções no projeto da máquina.

\section{AGRADECIMENTOS}

Ao Laboratório de Colheita, Ergonomia e Logística Florestal (DEF-CCA-UFES) pela infraestrutura concedida para a execução do trabalho; ao Conselho Nacional de Desenvolvimento Científico e Tecnológico $(\mathrm{CNPq})$ e à Fundação de Apoio à Pesquisa no Espírito Santo (FAPES) pelo apoio financeiro e concessão de bolsas; aos trabalhadores rurais e proprietários que permitiram a execução da pesquisa.

\section{STATUS DA SUBMISSÃO}

Recebido: 07/08/2011

Aceito: $26 / 10 / 2011$

Resumo publicado online: 27/10/2011

Artigo completo completo: 22/12/2011

\section{AUTOR(ES) PARA CORRESPONDÊNCIA}

\section{Nilton Cesar Fiedler, Renan Pereira Barbosa}

Departamento de Engenharia Florestal, Universidade Federal do Espírito Santo - UFES, Av. Governador Lindemberg, 316, Centro, CEP 29550-000, Jerônimo Monteiro, ES, Brasil e-mail: fiedler@pq.cnpq.br; nilton.fiedler@ufes.br

\section{REFERÊNCIAS}

Alves JU, Souza AP, Minetti IJ, Gomes JM. Avaliação da carga de trabalho físico de trabalhadores que atuam na atividade de propagação de Eucaliptus spp. In: Anais do I Simpósio Brasileiro sobre Ergonomia e Segurança do Trabalho Florestal e Agrícola; 2000; Belo Horizonte. Belo Horizonte: Ergoflor, 2000. p. 129-134.

Espinosa J. Manual de Ergonomia Florestal. Concepción: Laboratorio de Ergonomia de La Universidad de Concepción, 1999. 102 p.

International Ergonomics Association - IEA. Definição internacional de ergonomia. Santa Monica: USA, 2000. [cited 2010 jul. 9]. Available from: http://www.iea.cc/ what_is_ergonomist.html.

Iida I. Ergonomia: projeto e produção. 2rd ed. São Paulo: Edgard Blücher, 2005.

Montmollin M. A ergonomia. Lisboa: Gráfica Manuel Barbosa \& Filhos, 1990. 182 p.

Silva KR. Análise de fatores ergonômicos em marcenarias e do mobiliário do município de Viçosa - MG [dissertação] Viçosa: Universidade Federal de Viçosa, 1999. 97 p.

Vosniak J, Lopes ES, Fiedler NC, Alves RT, Venâncio DL. Carga de trabalho físico e postura na atividade de coveamento semimecanizado em plantios florestais. Scientia forestalis 2010; 38(88):589-598. 